\title{
Preface I
}

This special issue constitutes an excellent and representative testimony of the variety of contributions presented during YOCOCU 2016.

The reader will find that the 41 papers in this special issue cover a wide range of materials (stone, gypsum, lime, mortar, ceramics, metal, paper, videos, textiles, paintings, plastics, pigments ...), from different types of art and heritage: architectural and archaeological; contemporary and digital art; industrial heritage, vernacular, art caves and ethnographic heritage; museum collections, landscapes and intangible cultural heritage $(\mathrm{CH})$.

Among the techniques covered in this special issue, some innovative techniques, such as nanotechnology and nanomaterials, digital documentation, mobile apps, 3D technology, etc. are included, besides the more traditional ones for characterization, diagnosis, conservation and restoration (consolidation, protection, repairing, replacement and biocidal techniques).

One of the successes of the conference was to give a significant place to studies not always considered in this type of scientific conferences. In this regard, papers dealing with $\mathrm{CH}$ socio-cultural benefits and impacts, dissemination, tourism and economics, management, education, guidelines and management are present in this issue.

108 authors from 17 countries in four continents contributed to this special issue: China, Croatia, Germany, Greece, Italy, Mexico, Namibia, Pakistan, Portugal, Romania, Russia, Serbia, South Africa, Spain, Turkey, United Kingdom and the United States of America.

Most of the contributors are young students, researchers or professionals working in the field of $\mathrm{CH}$, to whom $\mathrm{YOCOCU}$ conferences are devoted, as well as all the YOCOCU associations (Italy, Spain, Belgium, Azerbaijan, Turkey, Croatia, Romania and Germany).

The first and main goal of YOCOCU is to create an international platform to foster the role of youth in the field of research in $\mathrm{CH}$ conservation and restoration, in all disciplines related to $\mathrm{CH}$, from the most modern and avant-garde to the traditional ones.

Some other objectives pursued by YOCOCU are to promote the conservation and value enhancement of cultural heritage; to give voice to young professionals and to provide them with tools and opportunities to develop their careers as well as the $\mathrm{CH}$ sector; and to match senior conservators with junior professionals.

I would like to acknowledge the reviewing tasks performed by the 25 reviewers, most of them members of YOCOCU 2016 Scientific Committee, for their time and effort, and who contributed to improve the quality of the papers.

I want also to express my gratitude to this journal, GE Conservation, for the confidence and the opportunity given for the dissemination of these papers, and for the excellent editing of this special issue.

Last but not least, thanks to my colleagues of the Petrology applied to Heritage Conservation research group, to YOCOCU Spain and to all the members of YOCOCU 2016' Organizing Committee. They made possible the conference, and therefore, this special issue.

I wish this publication will encourage young people, on the one side, to focus their interest on $\mathrm{CH}$, and on the other side, I hope that young people who are already working in the field of $\mathrm{CH}$ of all over the world, will attend next editions of YOCOCU international conferences.

\section{Monica Alvarez de Buergo}

Chair of YOCOCU 2016, Madrid (Spain), 21-23 September 2016

\author{
Geosciences Institute IGEO \\ Spanish Research Council CSIC and Complutense University of Madrid UCM
}

Youth in Conservation of Cultural Heritage YOCOCU - Spain association 